\title{
PELATIHAN PERAKITAN, INSTALASI DAN TROUBLESHOOTING KOMPUTER/LAPTOP PADA ANGGOTA ORGANISASI PMII KAB. BANJAR
}

\author{
Mirza Yogy K, Fathul Hafidh, Al Fath Riza \\ Fakultas Teknologi Informasi, Universitas Islam Kalimantan MAB \\ Email : mirza.yogy@gmail.com
}

\begin{abstract}
Hardware and Software are the main elements in information technology one of which is the computer. The computer itself is divided into two forms namely the type of portable or called laptop and Personal Computer or called PC. Computers are divided into two types namely Built Up and Assembled. Computer assembly is a technique of assembling and installing all hardware components to become a computer that can be used as it functions. Computer installation is the process of installing software into the computer to be useful as usefulness, while troubleshooting is to solve problems that occur both in hardware and computer software. Therefore, this devotion has a purpose so that the participants have knowledge in assembling, installing and troubleshooting computer technology either in personal use or in the field of business. This devotion is implemented in PMII Kab. Banjar, about 10 members who can follow the implementation of Community Service Activities.
\end{abstract}

Keywords: Installation, Technology, Troubleshooting, Assembling

\section{PENDAHULUAN}

Teknologi komputer baik dari sisi hardware (Perangkat Keras) dan software (Perangkat Lunak) berkembang secara cepat dan beriringan, hal dikarenakan saling keterkaitan satu sama lainnya. Pengguna disuguhkan berbagai macam bentuk, warna, ukuran dan versi terbaru dari teknologi tersebut tetapi kurang mengetahui tentang komponenkomponen apa saja yang terpasang, apa yang menyebabkan terjadinya kerusakan, bagaimana melakukan instalasi perangkat lunak, dan lainya. Banyak pengguna yang melek teknologi tetapi sebatas menggunakan saja, jarang dari mereka yang ingin memahami dan mengetahui dibelakang itu semua.

Peran komputer/Laptop dalam kehidupan sehari-hari sekarang ini sangat terasa penting. Berbagai aktifitas dapat dilakukan mulai dari pekerjaan rumah, pekerjaan kantor, tugas kuliah dan banyak lagi lainnya. Komputer terbagi menjadi 2 (dua) jenis, komputer Built Up dan Komputer Rakitan. Perakitan komputer adalah teknik merangkai dan memasang semua komponen-komponen perangkat keras agar menjadi sebuah komputer yang dapat digunakan sebagaimana 
fungsinya. Instalasi komputer adalah proses memasang perangkat lunak kedalam komputer agar berguna sesuai kegunaannya, sedangkan troubleshooting adalah melakukan pemecahan masalah yang terjadi baik pada hardware maupun software komputer.

\section{KHALAYAK SASARAN}

Khalayak sasaran dari kegiatan pengabdian kepada masyarakat adalah anggota PMII Kab.Banjar berjumlah 10 orang. Anggota PMII Kab.Banjar ini terdiri dari mahasiswa yang berasal dari berbagai macam Universitas ataupun Perguruan Tinggi lainnya.

\section{METODE \& MATERI KEGIATAN}

Metode pelaksanaan kegiatan pengabdian kepada masyarakat dilaksanakan melalui pelatihan dengan pemanfaatan modul yang telah disediakan yaitu dengan metode teori pembelajaran dan praktik langsung ditempat (bongkar pasang perangkat keras baik laptop maupun komputer). Selain itu, mereka juga diberikan contoh-contoh kasus troubleshooting yang sering dihadapi dilapangan dan melakukan uji coba terhadap hasil yang meraka rakit dan instalasi.
Melalui kegiatan pengabdian kepada masyarakat, pelatihan kepada para peserta (anggota PMII Kab.Banjar) dilakukan oleh beberapa instruktur profesional dibidangnya dengan materi pelatihan sebagai berikut :

1. Perakitan komputer dan laptop versi INTEL dan AMD

2. Instalasi dengan sistem operasi windows 8 dan aplikasi windows lainnya

3. Troubleshooting pada komputer Windows baik jenis INTEL ataupun AMD

\section{FOTO KEGIATAN}

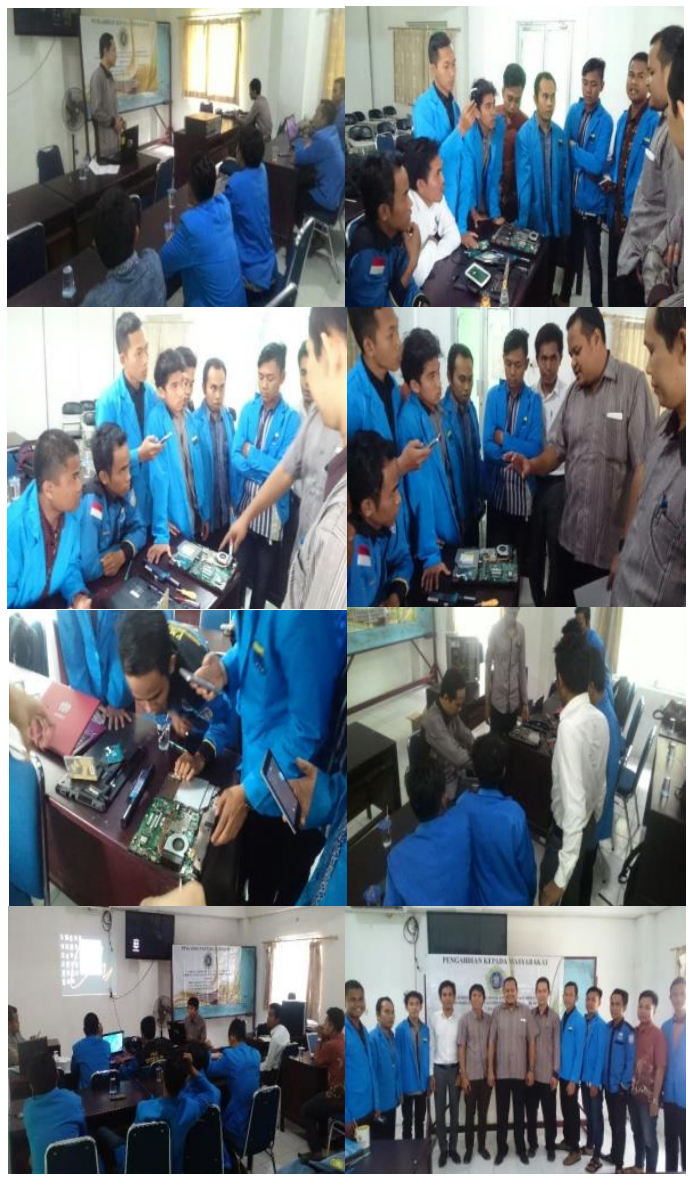




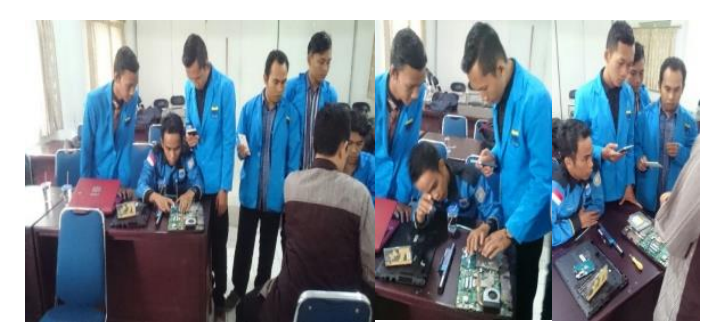

\section{KESIMPULAN}

Kegiatan Pengabdian Kepada Masyarakat yang dilaksanakan di PMII Kab. Banjar berjalan dengan lancar dan baik. Peserta terlibat sangat aktif dan sangat bersemangat dalam tanya jawab serta mempraktekkan apa yang diajarkan.

Dari hasil Kegiatan Pengabdian Kepada Masyarakat yang telah dilaksanakan, maka dapat diambil kesimpulan sebagai berikut :

1. Semua peserta sangat antusias mengikuti kegiatan ini karena materi yang diberikan sangat bermanfaat dan menarik bagi peserta serta membuat mereka melek IT.

2. $75 \%$ dari Peserta Pengabdian Kepada Masyarakat sudah berani berinisiatif untuk membuka usaha dibidang IT salah satunya tentang service Perangkat Keras dan Perangkat Lunak.

3. Materi Pelatihan Perakitan, Instalasi Dan Troubleshooting Komputer/Laptop Pada Aggota organisasi PMII Kab. Banjar diikuti dan dipahami $100 \%$ oleh seluruh peserta. Terlihat pengetahuan peserta dari hasil sebelum dan sesudah pelatihan dilaksanakan.

\section{DAFTAR PUSTAKA}

Aditya, Charisma Wahyu. 2011. Awas Ada Maling! 30 menit membobol komputer. Yogyakarta : MediaKom

Faisal, Lisa. 2007. Hacking Windows dan Pengamannya. Jakarta : Infokomputer.

Nugroho, Bunafit. 2013. Instalasi dan Konfigurasi Windows 8. Yogyakarta : Andi Offset.

Putra, Rahmat. 2008. Mengatasi Windows Error Dalam Waktu 5 Menit. Jakarta : Kawan Pustaka.

Wahana Komputer. 2005. Perakitan Komputer. Semarang : Andi. 